\title{
Turning Points in the INF Negotiations
}

\author{
Daniel Druckman, Jo L. Husbands, \\ and Karin Jobnston
}

On 8 December, 1987, U.S. President Ronald Reagan and Soviet General Secretary Mikhail Gorbachev met in Washington, D.C., to sign a treaty agreeing to eliminate all nuclear delivery vehicles in their arsenals with ranges between 500 and 5,500 kilometers. Known as the Intermediate-range Nuclear Forces (INF) Treaty, this agreement requires the United States to dismantle about 400 missiles, while the Soviet Union will have to dismantle approximately 1,500 such weapons within three years. This represents the first time since the nuclear arms race began in 1945 that an entire category of nuclear delivery vehicles has been eliminated from the arsenals of either superpower.

The INF Treaty represented the outcome of almost eight years of negotiation. The process began in December 1979, when the North Atlantic Treaty Organization (NATO) adopted its so-called Dual Track decision. NATO declared its intention to deploy 572 new U.S. missiles in five Western European countries beginning in 1983 in response to the deployment by the Soviet Union of its SS-20 missiles, which had commenced several years earlier. However, the alliance also committed itself to begin immediate negotiations for the elimination of this category of weapons, which would make the new NATO deployments unnecessary. Thus, NATO's actual deployment was tied to the failure of those negotiations to produce results prior to the 1983 deployment date.

The opening of the actual negotiations was delayed, however, due to both the Soviet Union's intervention in Afghanistan just two weeks after the NATO decision in 1979 and the election of a new U.S. president in 1980. Negotiations finally opened in late 1981 but did not produce any concrete results in time for the 1983 deadline. Negotiations were suspended in the wake of a Soviet walkout during 1984, while the United States began deploying missiles in the

\footnotetext{
Daniel Druckman is a principal study director at the National Academy of Sciences, 2101 Constitution Ave., NW, Washington, D.C. 20418. He is Adjunct Professor of Conflict Management at George Mason University in Fairfax, Va. Jo L. Husbands is a senior research associate at the National Academy of Sciences. Karin Johnston is a graduate student in the Department of Government and Politics at the University of Maryland.
} 
Federal Republic of Germany, Italy, and Great Britain. In early 1985, the Soviets agreed to reopen discussions within the context of a tripartite negotiation dealing simultaneously with intercontinental or strategic nuclear weapons, spacebased weapons, and intermediate-range nuclear forces. These negotiations remained largely stalemated until the 11-12 October, 1986 Gorbachev-Reagan summit conference at Reykjavik, Iceland, at which time major changes in attitude toward a possible INF agreement occurred. Throughout the following year, a series of Soviet concessions, especially an agreement to break a prior linkage between space-based defenses and INF weapons, as well as progress on the complex issues of verification, enabled the two countries to achieve the INF Treaty.

\section{Negotiators' Perspectives on INF}

This article focuses on the role of the president and the distinction between technical and policy functions in the structure surrounding a negotiation, as well as the influence of deadlines and unilateral initiatives on the process. The analysis is based on interviews with 15 members of the U.S. delegation and its supporting staff in Washington. ${ }^{1}$ Therefore, insights derived about this case are likely to be from the perspectives of working-level negotiators and agency staff members rather than high-level policymakers or outside analysts. These perspectives are especially valuable for students of the negotiation process. As informants, negotiators and support staff can provide a knowledge of internal processes unavailable to those not involved in the negotiation. As players, negotiators' perspectives are likely to be a source of influence on the process or, at least, reflect their experiences in that process. Moreover, the interviews provided a framework for respondents that encouraged them to conceptualize the process in certain ways. This framework emphasizes processes and structures discussed in the more general literature on negotiation and arms control. Illustrating an inevitable interplay between theory and case details, the lessons learned should contribute to an understanding of both international negotiation and superpower arms control issues. ${ }^{2}$

A key to understanding the INF Treaty, and other negotiating processes, is the concept of turning points. Turning points are defined as events or processes that mark the passage of a negotiation from one stage to the next, signaling progress from earlier to later phases ${ }^{3}$ The concept has been used to depict progress in such diverse negotiations as the U.S.-Spain base-rights talks (Druckman, 1986) and the North American Free Trade talks (Tomlin, 1989), and can be used to interpret the flow of events in other negotiations. It is employed here as a conceptual device for organizing the sequence of diverse events that occurred in the INF talks, showing how these events provided a momentum toward the agreement that was signed at the Washington summit in 1987. The analysis of this case also serves to expand the turning point concept by encompassing a wider range of negotiation activities within its purview.

Our respondents generally agreed about the events that should be regarded as turning points. These are shown in Table 1. Some of these events can be regarded as primarily substantive breakthroughs, as when Gorbachev proposed a "double-zero" option. Others are largely procedural, as when a summit was scheduled for December 1987 in Washington. These events suggest the importance of summitry, unilateral initiatives, and presidential involvement as 
influences on negotiation processes and outcomes. Each of these influences is discussed in the sections to follow. In addition, we discuss the role of technical information in the negotiation process, distinguishing between technical and policy roles. This is a particularly important issue in arms control talks, and our respondents provided a number of insights. Together with the other themes, this discussion provides a basis for lessons learned, summarized in a concluding section.

\section{The Value of Summitry}

Weihmiller (1987) presents lessons learned from the experience of U.S.-Soviet summitry from Presidents Roosevelt through Carter. He concluded that there is great diversity in the character and functions served by summits: "The record is replete with summits that have both improved and aggravated bilateral relations, yielded unexpected successes and unintended consequences, and have been accompanied by unrelated surprises as well as an unusual pattern of more aggressive behavior in their aftermath. Inconsistency has been their most notable characteristic and the hallmark of the summit experience to date (Weihmiller, 1987:146). Focusing more specifically on the relationship between arms control talks and summitry, Weihmiller notes both successes and failures and suggests two lessons:

- Summits are action-forcing events; in preparing for them, decisions must be made on matters that otherwise might not be resolved.

- The achievement of past agreements on strategic arms limitations at summits does not, in itself, provide convincing evidence that such matters are particularly well-suited to summitry or, alternately, that summits provide the optimal forum for making progress toward such agreements.

On the one hand, summits are events (or signals) that may serve to galvanize the bureaucracies to speed up the negotiating process conducted at lower levels. This was the case for the Reykjavik and Washington summits in the INF talks. On the other hand, they are not suitable forums for negotiating details, as the Reykjavik summit illustrated.

The three summits surrounding the INF talks (see Table 1) served several functions. The November 1985 meeting in Geneva took place following Gorbachev's announcement that French and British nuclear forces could be negotiated separately, removing a major obstacle to a bilateral agreement. During the summit, Gorbachev reinforced the seriousness of the purpose this move conveyed by also agreeing to delink INF from the Strategic Arms Reduction talks (START), taking place in Geneva. In addition to defining a bargaining space (the Soviet range of acceptable outcomes was perceived as overlapping the U.S. range), the meeting provided an opportunity for the two leaders to get acquainted, and they came away with mutual admiration and a conviction that they could work with each other. (Recent experimental evidence reported by Druckman and Broome, 1991, indicates positive effects for liking and familiarity on willingness to compromise in negotiations, although similar evidence for cases of international negotiation has not been provided.) 


\section{TABLE 1}

\section{INF Turning Points}

October 1985: In Paris, Gorbachev eliminates a major obstacle to an INF agreement by announcing that French and British nuclear forces would be removed from the agreement. This was the first indication that the Soviets were serious about moving the process forward.

November 1985: In Geneva, Reagan and Gorbachev meet, leading to mutually positive personal assessments and an agreement to keep the INF separate from START, so that an INF agreement could be reached without progress in START.

June 1986: A new Soviet proposal acknowledges that all SS-20s east and west of the Urals could be considered together in a reduction package. This proposal suggested that the Soviets were reevaluating their deployment of this system.

October 1986: Reagan and Gorbachev meet in Reykjavik. Viewed largely as a process or procedural turning point, Reykjavik brought senior officials from both sides together during a negotiation, a first for major intergovernmental negotiations. From this point forward, the process accelerated, since both leaders realized that the other was ready to negotiate seriously. A key understanding reached, perhaps before Reykjavik, was that both sides could keep 100 warheads in Europe. The understandings or agreements in principle took the form of proposals in Geneva at the round in November.

February 1987: Gorbachev states that an INF agxeement no longer depends on agreements reached on strategic and space weapons (SDI). (Gorbachev's initiative here indicates acceptance of an earlier U.S. proposal to delink.)

June 1987: Agreement reached allowing on-site inspections of manufacturing and storage facilities for INF missiles.

July 1987: Gorbachev proposes a "double-zero" option, making vetification much easier. This included elimination of all SRINF and LRINF systems in Europe and SS-20s in Asia, Negotiating delegations divided into working groups at this time, indicating that the mechanics of an agreement were being fleshed out.

September 1987: Agreement in principle to conclude an INF accord, although timing and verification procedures not specified.

October 1987: Both sides agree on a summit meeting set for December 7 in Washington. (Once announced, this served as an unofficial "deadline" for treaty signing.)

November 1987: Announcement that an agreement has been reached with only inspection details to be worked out; Shultz announces in Brussels that NATO will cease deploying about 200 of the remaining 464 planned GLCMs as soon as treaty is signed.

8 December 1987: Reagan and Gorbachev sign the treaty in Washington. 
All our respondents regarded the October 1986 meeting in Reykjavik as a critical turning point in the negotiating process. It provided the first opportunity for senior government officials to discuss details during the course of the negotiation. By reaching agreements in principle which became formal proposals during the next round in Geneva, this event effectively moved the negotiation to a new stage. From this point on, the process accelerated with a spate of initiatives from Gorbachev, which brought the Soviets much closer to the U.S. position, and an increased number of proposals and counterproposals being made at the table in Geneva.

Other reasons made the December 1987 meeting in Washington very important. The announcement of the summit in September set an unofficial "deadline" for completing an agreement. The upcoming event put enormous pressure on the bureaucracies to work out unresolved details and draft treaty language. As one of our respondents commented, summits are "action-forcing events. If you know a summit is coming up, know you have a treaty close to fruition, you know the president will want to sign it. It (INF) was ripe for the picking. You set a deadline, and there's never enough time, but you have to have that event out there as the catalyst or driver to get people to solve the problems."

The "end effects" seen in this case resemble the large concessions made by bargainers facing a deadline in laboratory experiments (e.g., Druckman, 1971; Druckman et al., 1972). A deadline forces negotiators to choose between available agreements, which may not be optimal, and the best alternative to a negotiated agreement, which may not be desirable. Referred to as a "decision dilemma," this choice is brought into relief in negotiations where a previous agreement terminates at a given time. (See Druckman's (1990) discussion of decision dilemmas in base-rights talks and Iklé's (1964) discussion of the threefold choice, which pits a desire to reach agreement against desires to continue negotiating or to abandon the talks.)

Some respondents resisted the idea that a deadline had been set. This may have been simply a matter of definition; one respondent preferred "target" to "deadline." While we found, in fact, no evidence that President Reagan actually said, "I want a treaty by the summit," the upcoming event spurred negotiators to move toward closure. Another source of reluctance to the idea of a deadline is political; one respondent argued that "some people will say there wasn't a decision made or a timetable attached because they are still stung by the criticism that we did the treaty 'in a hurry-up fashion.' The fact is that they could have worked on the treaty for the next 20 years. You don't arrive at an end product unless deadlines are set."

As evidenced, summit meetings serve several positive functions: defining a bargaining space, developing trust between leaders, conveying a seriousness of intent to reach agreement, and serving as a deadline for producing a treaty. According to Weihmiller (1987), however, these positive functions may not be universal; many summit experiences have been dysfunctional in terms of reaching agreements or improving relationships between nations. The success of these summits, as turning points, must be placed in the context of other events surrounding this case, such as Gorbachev's initiatives, Reagan's political ambitions, the changing relationship between the countries, and the relatively minor security implications of eliminating these weapon systems. 


\section{The Value of Unilateral Initiatives}

The INF Treaty can be understood in the context of a changing relationship between the U.S. and the Soviet Union, a change due at least in part to a stream of unilateral moves made by Gorbachev. Several of these initiatives concerned INF reductions, bringing the Soviet position closer to the U.S. proposals for an agreement. ${ }^{4}$ Four major initiatives are shown in the chronology: separation of the French and British forces from the U.S. systems (October 1985); including all SS-20s in a reduction package (June 1986); delinking strategic and space weapons from INF systems (February 1987); and a proposed "double-zero" option (July 1987). Whether viewed as concessions to the U.S. position or as "starting mechanisms" for moving the talks forward, the delegates and support staff interviewees saw these moves as major turning points. The 1985 and 1986 initiatives were made in anticipation of the Geneva and Reykjavik summits respectively. The 1987 moves resolved major sticking points, clearing the way for the scheduling of a summit at year's end. The "double-zero" proposal also led to a change in procedures at the negotiations, with delegates and experts dividing into working groups. This change signaled a transition to the next stage of the talks (Druckman, 1986). Both initiatives were made during a period of frenetic activity by bureaucratic actors in anticipation of the agreement in principle that was reached in September 1987.

The role of unilateral initiatives (UIs) in international relations has been analyzed and debated in recent literature. Effectively executed, UIs can serve to unfreeze a stalemate and move negotiations forward. (Experimental evidence is presented by Lindskold and his colleagues, 1986; case study evidence is discussed by Rose, 1988). The INF talks provide case evidence attesting to positive effects on a negotiation process. Less clear, however, is whether the UIs reflect changes in relations between the nations or provide an impetus for those changes: Additionally, the relationship may be circular, as Etzioni (1968) argued with regard to the unilateral moves made by Kennedy prior to the signing of the limited nuclear test-ban treaty. The implications for negotiations turn on the question of whether unilateral moves contribute to success without changes in the overall atmosphere of superpower relations. The interpretation of a move made by another may well depend on the nature of the relationship between the parties and the setting in which they interact, as suggested by research in cognitive psychology (see Nisbett and Ross, 1980). If this is so, then the impact of Gorbachev's UIs on the INF process was conditioned by concurrent changes in atmosphere. On the other hand, the initiatives may have contributed to improving the atmosphere, which in turn made the treaty possible. An understanding of the causal sequence of these factors, which has significant implications for negotiating strategy, awaits further research.

\section{The Value of Presidential Involvement}

Gorbachev's initiatives make clear the importance of his role in the INF process. Without similar high-level involvement on the U.S. side, however, those initiatives were unlikely to have resulted in a treaty. Our respondents generally viewed Reagan's interest in the success of the negotiations as a critical factor in getting an agreement. As one respondent commented: "I don't think anything happened until the President got involved. Though he can't be involved in every- 
thing, it only works when he gets involved-especially if the issue is controversial and if you have the split which existed in the Reagan administration between State and Defense."

Reagan's interest became manifest following the Reykjavik summit and reinforces the idea that the summit was a turning point in the process. While not communicated directly to his cabinet or advisers, a sense of priority, which translated into a perceived desire for an agreement, was conveyed by several actions. One such action consisted of siding with Secretary of State George Schultz against Secretary of Defense Casper Weinberger's opposition to a treaty. Another was to increase National Security Advisor Colin Powell's imvolvement in the process; he became the primary decision-maker on INF issues during this period. And a third action consisted of the increased involvement of National Security Council staff members in the interagency meetings convened to formulate positions for the negotiators in Geneva. As one respondent noted, "Once the president made it clear that he wanted the treaty, the NSC staff operated differently. They didn't have to browbeat dissenting members-only had to remind people that the President wants the treaty and they were the obstacles. The NSC staff began to reinforce this by going to the interagency groups and asking why no position had been formulated to send to Geneva." Together, these actions had the effect of accelerating the pace of the support and negotiation process without a corresponding change in the organizational structures within which those activities took place.

Presidential involvement also has important implications for the operation of the arms control policy-making process; capturing and holding the president's interest becomes crucial to success. This is relevant to the bureaucratic gamesmanship that accompanies policy-making, especially for controversial issues. One of the virtues of interviews is the insights they provide into the policy-making culture and conventional wisdom that shape bureaucrats' perceptions and influence their actions. If policymakers believe that presidential leadership is critical, they will watch the White House for cues and carefully assess the credentials of anyone claiming to bear the president's mandate. In the absence of salient cues, progress is difficult, since the advantage generally lies with opponents for any controversial issue that requires interagency agreement to move an issue ahead.

The importance of presidential leadership in the INF Treaty process is noted also by Reddy (1989). He credits Reagan with bold leadership, citing his firm but flexible strategy with regard to INF deployments, on the one hand, and withdrawals to meet Gorbachev's initiatives, on the other: "The extraordinary steps taken by both sides that made the INF treaty possible would have been impossible without direct and frequent involvement of Gorbachev and Reagan, their foreign ministers, and their senior military advisors" (Reddy, 1989:74-75). Based on these observations, he suggests more generally that "strong personal leadership at the highest level is needed to consummate armscontrol agreements" (Reddy, 1989:74). This lesson is supported by other analysts of nuclear arms control policy-making. Gray's (1986) examination of the U.S. political environment surrounding arms control negotiations led him to conclude that White House leadership is a necessary condition for success. As shown by the INF case, presidential involvement serves to set in motion a process that forges a policy consensus from divided agency positions. Similarly, Frye 
(1974) credits President Johnson for getting the agencies to prepare serious negotiating positions in anticipation of a SALT-ABM treaty. And Neidle concludes, as part of his reassessment of arms control goals, that "unless the President is deeply and continuously involved, there is little hope of achieving anything that is worthwhile" (1982:123). However, the needed presidential involvement may be hostage to the timing of election-year cycles. A number of the analysts note that a president's assessment of impact on either reelection or historical recognition may determine the extent of his involvement. Historical recognition may well have played a role in Reagan's desire for an INF agreement, and this was emphasized by several of the interviewees.

The kind of leadership needed for successful intergovernmental negotiation is captured in part by Young's (1989) concept of "entrepreneurial leadership." Citing effective leadership as a determinant of success in institutional bargaining, he describes entrepreneurial leaders as "actors who are skilled in inventing new institutional arrangements and brokering the overlapping interests of parties concerned with a particular issue-area" (Young, 1989:373). The actions taken by Reagan and Gorbachev consisted largely of propelling their respective bureaucracies to channel their efforts toward getting an agreement. They were entrepreneurial leaders in the sense of highlighting the goal and redirecting energies of bureaucrats without getting enmeshed in the process. Less concerned with the common good or with regime formation, they were motivated primarily by "a durable sense of self-interest" that, according to Young, does not detract from the important role these actors play. They ensure the achievement of desired agreements whether or not these agreements contribute to improved relationships over the long term. Reductions of INF weapons systems could be achieved without endangering perceived security concerns. It was a mutual goal that was achieved, due largely to the use of skillful tactics by key actors, including the presidents.

\section{Technical and Policy Roles in Negotiation}

The distinction between technical and policy roles in decision making is relevant to the INF talks, as well as to other arms control negotiations involving sophisticated weapons systems. The way in which these roles interact during the process has implications for the use of technical information in political negotiations, as well as other aspects of the nuclear policy process. For example, to what extent do calculations of verification uncertainties influence the willingness of political decision-makers to reach agreement? Our interviews addressed a number of issues concerning these roles. Our respondents generally recognized the relevance of the distinction in terms of needed expertise in an arms control negotiation. Some discussed the way in which these roles influence the process and their implications for the outcomes.

By technical roles, we refer to those persons with specialized training and expertise in the capabilities of weapons systems and verification. Experts may be members of a delegation. More often they are part of the support structure for a negotiation and are sometimes outside consultants or contractors. Political roles consist usually of high-level policymakers and officials assigned to the delegation, including the head of delegation and his or her deputies. The way that this distinction is manifested in structure and process has implications for the way technical information is used in negotiations. As one respondent com- 
mented: "Policy people always come in at the top and the technicians will implement those policies . . . Not too many technical people are at the top of (even) very technical negotiations-their influence goes through political people, though it's conditioning in a way. Policy people need to rely on the technical knowledge of experts."

The structure of most U.S. government agencies creates somewhat different career paths for its technical and policy-oriented decision-makers. An analysis of the biographical sketches of 193 nuclear-policy decision-makers in four administrations indicated two broad types of decision makers. One type is a technically trained (i.e., engineer, scientist) bureaucratic middle-manager, largely apolitical in the sense of working under both Republicans and Democrats. Another type is a policy-oriented, entrepreneurial, high-level official, who for the most part works for only one party. The technically trained type works primarily in the Department of Defense and the military services, while the policy-oriented type is distributed more evenly across the relevant agencies, with particular concentration in State and the Arms Control and Disarmament Agency (ACDA). ${ }^{5}$ One implication of these findings is that the two roles differ in terms of opportunities for mobility and influence, with the technicallyoriented personnel having fewer opportunities than policy-oriented decisionmakers.

The distinctions between these roles made within the government agencies are also apparent within the negotiating delegations. The interviewees emphasized that the policy-oriented delegates largely determined how technical information would be used in the negotiations. Technical experts were used primarily during two phases of the extended negotiation process. Their opinions were sought during the preparatory sessions when alternative options for proposed agreements are evaluated in terms of what can be done (technical considerations regarding the dismantling of weapons systems and their verification) and what ought to be done (political considerations regarding a national defense posture). These early discussions of technical-political trade-offs provide the greatest opportunity for influence by technical experts, whether inside or outside of government: outside expertise was sought from the Sandia labs, for example, during this phase of the INF talks. "This work had been going on for some years, so there was a body of knowledge already developed ... technical people creating these concepts and their applications were assisted by the intelligence people . . . you're very reliant on these people to determine what the limits are, what's possible and not possible."

Technical expertise was also sought during the later phases of the negotiations, when the delegations were divided into specialized working groups. The groups dealt primarily with such issues as destruction and inspection. The results of these discussions are contained in technical annexes to the treaty. One respondent commented: "If you have the parameters of a decision, and the parameters of an agreement, there is an enormous amount of detail that goes into it. This is where you can talk of the difference between policy and technical (roles)the execution of the details is handed over to the technical people from the policy people."

Even as the negotiation process moved from general concepts to detailed issues, the technical support sought was subordinated to the political considerations that inevitably drove the final decisions. As one respondent remarked: 
"In the final analysis, so many of the questions are uncertain and technocrats can't drive the answers. So, the policy community needs to know technical details; but the details won't resolve the question." Another commented that "when you get into policy issues that become major issues for the government, you can't convince policy makers that they're unable to implement a policy because the technicians say it's not going to work out well-unless it's a showstopper with technical opposition across the board."

Specialized information serves other functions in the negotiation process. It may be used tactically as an "excuse" to prevent agreements or to slow the process until a study is completed; at one point in INF, for example, a technical expert was brought in to argue for a site inspection procedure that almost everyone involved regarded as suspect. As deliberate or unconscious allies of policy makers opposed to a particular policy, "technical people are very good sources of reasons to slow the whole process down." Technical information may also inform the process from the outside in ways that could not be accomplished by "inside" perspectives. While the INF negotiators usually did not seek outside perspectives, interviewees noted the value of such information if timed appropriately to coincide with needs felt by the delegation and supporting staffs. Technical experts were sometimes brought "on board" temporarily, thus absorbing outside advice into the process. This was done toward the end of the INF process, for example, when one of the key American experts on the Pershing II missile was brought over to Geneva to advise the delegation. They also commented on the use of outside perspectives in providing bureaucratic weight to arguments. ${ }^{6}$ Together, the various functions served by technical information call attention to the political value of the advice. While the advice is offered by specialists, inside or outside of government, its use is controlled by the higherlevel nonspecialists who have policy orientations.

\section{Conclusions and Implications}

The turning points analyzed in this article were events that occurred after a period of no progress or after impasses. Each turning point served to propel the talks to a new stage, building up momentum toward the agreement. Some of the turning points (listed in Table 1) were primarily substantive breakthroughs (delinking issues, double-zero proposal), while others were procedural (scheduling and holding summits). Both kinds provided opportunities for defining a bargaining space within which negotiators could develop acceptable trade-offs, leading to the agreed package. Such critical junctures in the talks are similar to the concept of frame-breaking changes in the literature on career development. According to London (1988), these are periods in an individual's career during which new learning occurs: examples are the first year, new assignments, transfers to different locations or to new work environments. These are times when a person is likely to be receptive to feedback and responsive to encouragement for undertaking new tasks, developing new skills, and so on. Similarly, turning points in a negotiation provide opportunities for changing the direction of the talks, for viewing them in a new way thanks to frame-breaking insights. Whether we study careers over long time spans or negotiations over relatively shorter time periods, these concepts are useful ways of thinking about the life cycle of a process. 
The turning points in the INF negotiations were a result of actions taken at higher levels. They illustrate the general proposition that presidential policy decisions drive intergovernmental negotiating processes. Similar findings were obtained in an earlier study of base-rights negotiations (Druckman, 1986), leading to the lesson that domestic or international events, external to the negotiation and not under the control of negotiators, can largely determine the outcome. Other examples of the importance of external events suggest that international negotiation is a microcosm of international politics, although decisions made by negotiators may feed back into the policy-making process. (See Druckman and Hopmann, 1989, for a review of the case study evidence on internal versus external factors.) This perspective highlights the negotiator-as-delegate role, a role in which the negotiator is highly accountable to policymakers and has little latitude for making decisions. These dimensions-accountability and decision latitude-may be distinguishing features between negotiating settings, such as international versus domestic negotiations. It would be interesting to depict various negotiation settings in terms of these dimensions with, perhaps, the international negotiator categorized as being "high" on accountability but "low" on decision latitude, while buyer-seller interactions may have the opposite profile. Further implications for research could be developed from such a taxonomy.

What, then, are the implications of this role for activities of international negotiators? One implication is that they function primarily as monitors of the unfolding process. Monitoring consists of determining the extent to which various parties maintain an interest in the negotiation process. The parties consist of the opposing negotiating team(s), the executive departments being represented, legislatures that have to ratify the agreement, and other nations with a stake in the outcome. This is an assessment problem that emphasizes the representational aspects of negotiating. Another implication is that they must be alert to events or decisions that can fundamentally alter the substance or tone of the negotiation. A failure to respond to these events could result in lost opportunities for progress. In fact, these events become turning points due largely to the actions taken by negotiators and support staff. The Reykjavik summit (October 1986) produced agreements in principle from which serious proposals were crafted for presentation in the next round; Gorbachev's doublezero initiative (July 1987) led to the creation of working groups that concentrated on the details for an agreement. Without recognizing these events as significant departures from "business as usual," their impact on the negotiation would be minimal and their analytical significance would be negligible. After all, the identification of critical junctures for analysis is a retrospective exercise based on access to the full record of the completed talks.

Each of the factors discussed in this article is a particular aspect of the bureaucratic and leadership processes surrounding a negotiation. Together, they reveal a larger process that includes interactions at the highest levels outside the formal talks, decisions made by leaders outside the negotiating framework established at the table, bureaucratic politics, and a stratified division of labor between different types of players in the process. The actions taken at the highest levels consisted of mutual decisions (often reached at summits) to accelerate the talks, and initiatives taken by one side to break deadlocks. The actions taken within U.S. bureaucratic departments were responses to presidential agenda set- 
ting, resulting in the proposed packages presented at the table. Those responses were critical to progress and made it possible to interpret the higher-level decisions as the turning points of the negotiation. They also were responses made primarily by policy-oriented decision-makers whose expertise was in conflict management and diplomacy rather than in technical knowledge about weapons systems.

The extent to which the lessons learned from the INF negotiations apply to other cases as well remains to be discovered. Generality is an issue that can be addressed through the systematic comparison of diverse cases. Such comparisons would entail an examination of cases that vary in terms of extent of leadership, initiatives, and summitry, gauging the effects of these variables on the outcome. By accumulating evidence in this manner, it would be possible to assess the generality of these factors as driving forces on international negotiation. The success of the INF negotiations is attributed to the presence of all these factors acting together. Whether this particular configuration determines the outcome of other negotiations awaits the results of further case study analyses.

\section{NOTES}

1. The agency breakdown among our respondents was as follows: four from the Arms Control and Disarmament Agency, three from the State Department, three from the Defense Department, two from the National Security Council, two from the Joint Chiefs of Staff, and one from the Defense Intelligence Agency. Four respondents were at the Deputy Assistant Secretary level or above, while the others were senior analysts or office directors. Twelve were civilians, while three were military officers; 12 were primarily policy-oriented decision makers while three were primarily technical decision makers. Finally, six respondents worked with the INF delegation in Geneva while nine worked in support roles in Washington.

2. This study was conducted as a project for the National Research Council's Committee on the Contributions of Behavioral and Social Science to the Prevention of Nuclear War. Special thanks go to William Estes for his support of the project. Pamela Lanman assisted in the analysis of background data on policy and technical decision makers. Our respondents deserve special thanks for allowing us to interview them and to share with us their many insights into the INF process. The conclusions are those of the authors and do not necessarily reflect the views of the National Research Council.

3. The turning point concept, as used in this study, concerns a positive event that moves the process toward an agreement. It can, however, also be used to refer to events that have a negative impact on the process, such as an event that triggers an impasse.

4. Some U.S. officials we interviewed stressed that these were not initiatives, but concessions, a politically important distinction for the Reagan administration, which was stung by the credit Gorbachev received in Europe and elsewhere as a peacemaker. However one defines them, the impetus for agreement clearly came from the Soviet leader.

5. These results were derived from statistical analyses of 15 background characteristics coded from the profiles of 193 political appointees serving in the first and second Reagan administrations, the Carter administration, and the Ford administration. The data were collected by Joshua Handler for the John D. and Catherine T. MacArthur Foundation and made available to us for our analysis. Detailed results of cross-tabulations are available from the authors.

6. On the question of outside expertise, one respondent suggested four broad functions for technical experts. One is to provide a "sanity check" for validating proposals. Another is to contribute to the solution of specific problems, often leading to a strengthening of one or the other side in the debate. Third, experts are consulted as part of a process of consensus building, because they often provide links to different bodies of government. And, fourth, they can deal with issues that the system is not ready to entertain. They serve to initiate the intellectual debate before the government can-a function that cannot be served easily by "insiders." 


\section{REFERENCES}

Druckman, D. (1971). "The influence of the situation in interparty conflict." Journal of Conflict Resolution 25: 523-554.

_-_ (1986). "Stages, turning points, and crises: Negotiating military base rights, Spain and the United States." Journal of Conflict Resolution 30: 327-360.

- (1990). "Three cases of base-rights negotiations: Lessons learned." In U.S. Bases Overseas, edited by J. W. McDonald, Jr, and D. B. Bendahmane. Boulder, Colo.: Westview.

Druckman, D., and Broome, B. J. (1991). "Value differences and conflict resolution: Familiarity or liking?" Journal of Conflict Resolution, in press.

Druckman, D., and Hopmann, P. T. (1989). "Behavioral aspects of negotiations on mutual security." In Bebavior, Society and Nuclear War, edited by P. E. Tetlock, et al. New York: Oxford University Press.

Druckman, D., Zechmeister, K., and Solomon, D. (1972). "Determinants of bargaining behavior in a bilateral monopoly situation; Opponent's concession mate and relative defensibility." Behavioral Science 17: 514-531.

Etzioni, A. (1968). "Social-psychological aspects of international relations." In Handbook of Social Psychology, edited by G. Lindzey and E. Aronson, Vol. 5. Reading, Mass: : Addison-Wesley.

Frye, A. (1974) ). "U.S. decision making for SALT:" In SALT: The Moscow agreements and beyond, edited by M. Willrich and J. B. Rhinelander. New York: The Free Press.

Gray, R. C. (1986). "The internal dynamics of U.S. nuclear arms control policymaking." Part V of Fundamentals of Nuclear Arms Control. Report prepared by the Congressional Research Service for the Subcommittee on Arms Control, International Security, and Science, Committee on Foreign Affairs, U.S. House of Representatives.

Iklé, F. C. (1964). How nations negotiate. New York: Harper and Row.

Lindskold, S., Betz, B., Walters, D. S. (1986). "Transforming competitive or cooperative climates." Journal of Conflict Resolution 30: 99-114.

London, M. (1988). Developing managers. San Francisco: Jossey-Bass.

Neidle, A. F. (1982). Nuclear negotiations: Reassessing arms control goals in U.S.-Soviet relations. Austin, Tex.: Lyndon B. Johnson School of Public Affairs.

Nisbett, R., and Ross, L. (1980). Human inference: Strategies and shortcomings of social judgment. Englewood Cliffs, N.J.: Prentice-Hall.

Reddy, L. (1989). "Practical negotiating lessons from INF." The Washington Quarterly (Spring): $71-81$.

Rose, W. M. (1988). U.S. unilateral arms control initiatives: When do they work? Westport, Conn.: Greenwood Press.

Tomlin, B. W. (1989). "The stages of prenegotiation: The decision to negotiate North American free trade." In Getting to the Table, edited by J. G. Stein. Baltimore: Johns Hopkins University Press.

Weihmiller, G. R. (1987). "U.S.-Soviet summitry: Lessons learned." In U.S.-Soviet Summitry: Roosevelt through Carter, edited by J. W. McDonald, Jr. Washington, D.C.: Foreign Service Institute, U.S. Department of State.

Young, O. R. (1989). "The politics of international regime formation: Managing natural resources and the environment." International Organization 43: 349-375. 